\title{
Dispositivos de informação: arquivos, memórias e informação'
}

\author{
Information Dispositif: Archive, \\ memory and information
}

\author{
Derek Warwick da Silva TAVARES² \\ José Mauro Matheus LOUREIRO²
}

\section{Resumo}

O artigo aborda as dinâmicas do fenômeno informação como instrumento de desenvolvimento das lógicas e dos valores presentes nos quadros da memória, construídos e geridos no interior dos espaços arquivísticos. Para tanto, este estudo privilegia a noção de "dispositivo" tal como elaborada na obra de Michel Foucault e uma de suas derivações como os "dispositivos de informação", além ainda das concepções filosóficas e sociológicas sobre a memória social e o arquivo. Os conceitos e as noções empregadas são desenvolvidos em uma perspectiva privilegiada da inter-relação entre Ciência da Informação, Filosofia e Ciências Sociais, permitindo perceber que o movimento entre a informação, os arquivos e as memórias, quando ativado no interior desses "dispositivos", delineia tipos específicos de saber, poder e sujeitos submetidos a contextos sociais, políticos e econômicos específicos. Conclui-se ao fim que a memória coletiva constitui-se como um "dispositivo" composto de discursos de verdade, apresentado na condição de arquivo, isto é, como conjunto de regras que facultam o emergir, em uma determinada época, de um tipo de discurso capaz de agir sobre os homens, tornando-os sujeitos de certo conjunto de memórias.

Palavras-chave: Arquivo. Ciência da informação. Dispositivo. Informação. Memória.

\begin{abstract}
The piece of research analyzes the dynamics of information phenomenon as a development tool and the logic of the present values in the tables of memory built and managed within the archival spaces. Therefore, this study favors the notion of "dispositif" as elaborated in the work of Michel Foucault and its derivations as "information dispositif". The concepts and notions employed are developed in a unique perspective of the interrelation between Information Science/Philosophy/Social Sciences. They are letting you know that the movement of information, archive and memories, when activated within these "dispositive", delineate specific types of knowledge, power and subjects undergoing social, political and economic specific. It concluded at the end that the collective memory is constituted as a "dispositive" made up of real speech shown in file condition, that is, as a set of rules which give emerging at a certain time of a type of speech can to act on men, making them subject to certain set of memories.
\end{abstract}

Keywords: Archive. Information science. Device. Information. Memory.

\footnotetext{
1 Artigo elaborado a partir da dissertação de D.W.S. TAVARES, intitulada "Dispositivos de Informação: arquivos, memórias e informação. Universidade Federal da Paraíba; 2015.

2 Universidade Federal da Bahia, Instituto de Ciência da Informação. R. Basílio da Gama, s/n., Canela, 40110-100, Salvador, BA, Brasil. Correspondência para/Correspondence to:D.W.S.TAVARES.E-mail:<derek_mg@hotmail.com>.

Apoio: Coordenação de Aperfeiçoamento de Pessoal de Nível Superior.

Recebido em 22/7/2015, reapresentado em 18/3/2016 e aprovado para publicação em 7/6/2016.
} 


\section{Introdução}

O arquivo compreende duas instâncias distintas, porém, complementares. A primeira refere-se à guarda e à hermenêutica, enquanto a outra diz respeito a sua constituição como espaço de saber, poder e subjetivação em que o fenômeno informação é organizado e articulado a fim de subsidiar as construções da memória social. No interior dessas instituições, diversos processos são desenvolvidos para a geração e aplicação de normas, padrões e estratégias de recuperação da informação, voltados para o aperfeiçoamento de ações institucionais, governamentais e políticas. Tais dinâmicas atuam internamente a partir de enunciados específicos que formulam discursos e desenvolvem práticas sociais de subjetivação, por meio dos documentos e das ações documentárias.

Nesse sentido, o estudo constitui uma primeira abordagem acerca das dinâmicas do fenômeno informação nas construções da memória social, desenvolvidas no interior dos espaços arquivísticos, privilegiando a noção de "dispositivo", tal como elaborada na obra de Michel Foucault e, posteriormente, desenvolvida por alguns autores no âmbito da Ciência da Informação sob a denominação de "dispositivo de informação" (WILKE; JARDIM, 2006; WILKE, 2009). O emprego dessa noção permitiu refletir acerca das lógicas e dos valores presentes na inter-relação informação/memória social, considerando as teorias e as ações informacionais adotadas nas instituições arquivísticas, sobretudo no que tange às técnicas de avaliação e de seleção documental. Intenta-se refletir acerca das estratégias arquivísticas que constroem, condicionam e atualizam a memória em seu aspecto coletivo e social, constituindo os "dispositivos de informação".

\section{Do "dispositivo" ao "dispositivo de informação"}

A noção de "dispositivo"encontra-se presente em diferentes momentos do conjunto literário das publicações de Michel Foucault e criteriosamente articulada a todo o seu sistema de pensamento, composto por três eixos: arqueológico, enquanto campo de estudo das formações discursivas; genealógico, a partir da inserção do poder na ordem discursiva; e ético, na sua concepção de subjetividade e na atuação direta no comportamento dos homens. O desenvolvimento dessa noção decorre, sobretudo, da problemática que envolve os seus estudos relacionados às "ordens do discurso". Em um primeiro momento, ao trazer à tona a questão do saber, suas pesquisas centravam-se numa "arqueologia dos saberes", ou seja, na investigação das condições, formulações, seleções e estabelecimentos dos discursos na sociedade. A esse tipo de processo, Foucault denominou "Epistemé, ou dito de outra maneira," como o dispositivo estratégico que permite escolher, entre todos os enunciados possíveis, aqueles que poderão ser aceitáveis no interior, não digo de uma teoria científica, mas de um campo de cientificidade, e a respeito de que se poderá dizer: é falso, é verdadeiro" (FOUCAULT, 2010a, p.247).

A partir da década de 1970, ocorre no interior do pensamento foucaultiano aquilo que os estudiosos do seu pensamento denominam "virada genealógica". Tal "virada" decorre, principalmente, das questões que envolvem o campo dos discursos, compreendido como saberes, e o campo do poder, tomado como relações de força. Nesse momento, diferentemente da arqueologia que buscava investigar a racionalidade discursiva, a "genealogia" pautará seus estudos na ordem do poder, isto é, compreende os discursos como produtos das relações de força. Essa mudança de rumo em suas pesquisas deve-se à pressuposição de que a "epistemé" deveria ser observada não só do ponto de vista discursivo, mas também como um processo que abrange aspectos não discursivos. Ao realizar essa transição nos seus estudos, desloca as questões relativas à "epistemé", privilegiando agora a noção de "dispositivo" compreendido como:

Um conjunto decididamente heterogêneo que engloba discursos, instituições, organizações arquitetônicas, decisões regulamentares, leis, medidas administrativas, enunciados científicos, proposições filosóficas, morais, filantrópicas. Em suma, o dito e o não dito são os elementos do dispositivo. O dispositivo é a rede que se pode estabelecer entre estes elementos. [...] (Ou ainda) um tipo de formação que, em um determinado momento histórico, teve como função principal responder a uma urgência (FOUCAULT, 2010a, p.244).

O emprego da noção de "dispositivo", constituído de elementos heterogêneos, permite estabelecer uma rede entre o discursivo e o não discursivo, o dito e o não 
dito, a fim de descrever uma determinada formação histórica (FOUCAULT, 2010a, p.244). Dessa forma, tal noção é entendida como mecanismos de poder entrecruzados socialmente, integrando a condição humana, agindo como um apelo, atraindo e extraindo as estranhezas pelas quais se desvela e por onde é possível governar o pensar e o agir sob e para o outro (FOUCAULT, 2009a, p.52).

Nesses termos, o filósofo Giorgio Agambem oferece também a possibilidade de descrever o "dispositivo" como:

Um conjunto de práxis, de saberes, de medidas, de instituições cujo objetivo é de administrar, governar, controlar e orientar, em um sentido em que se supõe útil, os comportamentos, os gestos e os pensamentos dos homens (AGAMBEN, 2009, p.39).

O "dispositivo" articula as assimetrias discursivas/não discursivas e as formas de ocultação e produção de verdades por meio de um conjunto articulado ou não de saberes e poderes que produzem subjetividades. Nesse sentido, compreende-se o "dispositivo" enquanto composição multilinear que funciona na sociedade como estratégias de governo, no sentido largo e antigo de mecanismos e procedimentos destinados a conduzir os homens, a dirigir a conduta dos homens, a conduzir a conduta dos homens"(FOUCAULT, 2011, p.53), e de subjetivação, as quais, por sua vez, respondem e funcionam por meio de relações de saber/poder. Logo, o "dispositivo" é uma estratégia que atua na transformação dos seres em sujeitos, através da ação de diversos outros "dispositivos", bem como de agenciamentos que geram regimes, discursos e poderes de "governamentalidades" inseridos na condição de um conjunto de dispositivos, aparelhos jurídicos e administrativos que, no uso de técnicas e estratégias, tomam a população enquanto objeto de uma racionalidade governamental.

O conjunto dos fluxos informacionais que permeiam transversalmente os coletivos humanos enquanto fenômeno político constitui-se como um "dispositivo" possuidor da potência de derivação, ou seja, é simultaneamente produto e produtor de ações que geram regimes e discursos na sociedade contemporânea. No campo das ciências modernas e contemporâneas, a informação tem sido pensada e utilizada de maneira "purificada" (LATOUR, 1994), isto é, sempre acionada na busca de uma verdade ou de uma certeza que intenta isolar as incertezas.

A "purificação" nesse caso, tal como pensada por Bruno Latour, seria a estratégia de existência dos modernos que"estabeleceria uma partição entre um mundo natural que sempre esteve aqui, uma sociedade com interesses e questões previsíveis e estáveis, e um discurso independente tanto da referência quanto da sociedade" (LATOUR, 1994, p.16). Assim, compreender a atividade de "purificação" significa perceber a dificuldade que os modernos enfrentam na explicação dos fenômenos que se multiplicam em natureza híbrida. Logo, a prática de "purificação" reflete nos quadros das ciências modernas, que buscam fortalecer a dicotomia entre humanos e não humanos, cultura e natureza, em meio à proliferação dos híbridos. Em tais ações, os conceitos absorvem o espírito "moderno" das ciências da razão e anulam os aspectos que se encontram dispersos na natureza e que fazem parte dos fenômenos. Os fluxos informacionais enquanto elemento de sentido, controle, poder e subjetividade, apresentam-se então como um "dispositivo" contemporâneo voltado para a formalização e a condução das vivências humanas.

A utilização da noção de "dispositivo" para o estudo do fenômeno informação, no campo da Ciência da Informação, deu-se no escopo dos estudos referentes à "política de informação", a partir dos estudos de Frohman (1995) e González de Gómez (1996). Wilke (2009), empreendendo a ampliação do conceito de regime de informação, propõe a noção de "dispositivo de informação". Nessa perspectiva, entender a informação como "dispositivo" requer considerar o saber, o poder e a subjetividade - elementos axiais do pensamento foucaultiano -, bem como suas condições históricas de proveniência. Essas condicionantes derivam do fato de que os dispositivos, por mais que se apresentem ou pretendam ser compreendidos como elemento técnico e estratégico, são na realidade definidos por suas condições de linguagem e historicidade. O objetivo, consequentemente, não é dizer "eis o que é discursivo, eis o que não é" (FOUCAULT, 2010a, p.247), ou qual é o dispositivo - mas sob quais condições e por quais linguagens, técnicas, instrumentos e estratégias o dispositivo aparece e atua enquanto tal na sociedade. 
Os dispositivos se configuram, portanto, como mecanismos que em sua formação apresentam-se de maneira homogênea, interligando saberes, poderes e subjetivação, mas que, em sua forma aparente, são heterogeneamente complexos, múltiplos, variados e inconstantes. Suas linhas atravessam todo o espaço e duram curtos, médios e longos períodos, constituindo a base de influência e sustentação dos regimes de enunciados e de informação.

\section{Memória, arquivo e "dispositivos de informação"}

As pesquisas referentes à memória são desenvolvidas em diferentes áreas do conhecimento, destacando separadamente seu caráter individual, coletivo-social e/ou a interpenetração dos recortes anteriores.

A memória, destaca Ricouer (2007), é o ato de lembrar e esquecer, sendo sua principal característica, portanto, a seletividade. A evocação mnemônica decorre das necessidades do presente, a partir da existência de lembranças. Essas necessidades são destacadas por Pollack (1992) como aquelas que organizam, estruturam e enquadram a memória a partir de princípios e de vontades políticas não necessariamente vinculadas à ordem daquilo que é oficial ou geral. Além do mais, aquilo que é considerado marginal e secundário incorpora-se à construção da memória, tornando-a um fenômeno consciente ou inconsciente (POLLAK, 1992).

Indagando como se conhece o passado, Lowenthal (1998) afirma que as lembranças consistem em coisas lidas, ouvidas ou vividas em épocas pretéritas.

Toda consciência atual se funda em percepções e atitudes do passado; reconhecemos uma pessoa, uma árvore, um café da manhã, uma tarefa, porque já os vimos ou já os experimentamos. E o acontecido também é parte integral de nossa própria existência (LOWENTHAL, 1998, p.64).

A concepção de Lowenthal (1998) encontra-se enraizada no pensamento bergsoniano acerca da memória e da "duração" ('durée'). O tempo da memória, assinala Bergson (2006, p.175), é sempre o tempo do passado, ou seja, aquele momento instantâneo que encerra o momento ininterrupto do presente. Este último configura-se, não como aquilo que é agora, pois esse momento (agora) não mais existe, mas necessariamente o presente será aquilo que se faz, ou seja, o presente é movimento (motor), é devir. Dessa forma, "nós só percebemos, praticamente, o passado, o presente puro sendo o inapreensível avanço do passado a roer o futuro" (BERGSON, 2006, p.176). O tempo da memória, portanto, é o tempo do passado, aquele que funciona como subsídio para os sistemas sensório-motores realizarem análises da experiência a partir do presente, em vias do presente-instantâneo ou do presente-projetivo.

Inspirado por essa linha de pensamento, Murguia (2010, p.18) argumenta que"a memória seria uma espécie de cordão que amarraria nossos atos e pensamentos, permitindo uma continuidade que, ao longo de um período de tempo, articulasse nossa existência".

O passado, então, é uma construção humana no tempo e no espaço, permeado por influências e por confluências das relações existentes nos grupos humanos. É nesse sentido que a memória é tida por Halbwachs como coletiva. Desse modo, a memória coletiva é o produto consciente e inconsciente de uma realização no presente, em vias do futuro, cujo uso da lembrança enquanto passado é fruto do "efeito de várias séries de pensamentos coletivos emaranhados, à qual [...] não podemos atribuí-la exclusivamente a nenhuma dentre elas" (HALBWACHS, 1990, p.52). Nesse sentido, esse tipo de memória busca na lembrança das práticas, dos hábitos e dos fatos realizados individualmente ou em grupo formas de consolidação social. Conforme Ricouer (2007, p.129) aponta:

É por analogia apenas, e em relação à consciência individual e à sua memória, que se considera a memória coletiva como uma coletânea dos rastros deixados pelos acontecimentos que afetaram o curso da história dos grupos envolvidos, e que se the reconhece o poder de encenar essas lembranças comuns por ocasião de festas, ritos, celebrações públicas.

Independentemente da abordagem do fenômeno da memória, destaca Murguia (2010) que é fundamental pensá-la na sua dinamicidade, ou seja, nos fluxos de lembrança e esquecimento. Essa característica dá-se por meio dos dispositivos de regulação, de autorização, de controle dos discursos e de práticas de informação. Tais elementos balizam as representações, ângulos e limites daquilo que é e foi criado, concebido e manipu- 
lado como sendo o passado de um grupo social, por meio de um discurso de verdade.

A memória coletiva e a memória social são conceitos ou derivações distintas de um mesmo fenômeno: a memória. A coletivização ou socialização de ambas são condições essenciais para um fenômeno único, porém construído por interconexões entre o passado-presente-futuro e distintas representações que permanecem em um fluxo de mudanças permanentes. Abordar os quadros memorialísticos exige considerar suas assimetrias, pois a memória coletiva (e/ou social) tal como se apresenta nos seus conceitos é somente a unidade daquilo que representa, mas não a multiplicidade do que é representado.

Em sua análise do conceito clássico de arquivo, Derrida (2001, p.11) afirma que em um primeiro momento essa instituição pode ser vista como resultado de uma inscrição tipográfica (material ou subjetiva) ou como um acúmulo de coisas sobre coisas. Dois princípios iniciais sustentam essa ideia de arquivo a partir da interpretação da palavra "arkhê": o primeiro, histórico, físico, temporal ou ontológico, indica que o arquivo é um lugar onde as coisas começam e se processam; o segundo princípio, da ordem das leis ou da nomologia, mostra que o arquivo responde a um conjunto de regras e de ordens estabelecidas, exercidas e cumpridas pelos homens de poder. Estes últimos, conhecidos e detentores do poder de comando, possuem significação derivada da palavra arkheîon que significava originalmente o espaço dos arcontes (os magistrados). Murguia (2010, p.12) chama atenção que "não devemos pensar que esses documentos eram unicamente leis e disposições da forma em que as entendemos hoje. Isso porque, na época, a lei, o mito fundador, a interpretação religiosa eram inseparáveis".

$\mathrm{O}$ arquivo, assim, longe de ser um espaço unicamente de guarda, caracterizava-se também por ações hermenêuticas, ou seja, primeiras interpretações e representações documentais. Derrida (2001, p.14) ressalta ainda que essa instituição configura-se, sobretudo, como um lugar de organização ou um espaço de consignação (reunião).

A partir da noção de a priori histórico, Foucault (2009b, p.146), por sua vez, acredita que a ideia de arquivo surge sob a lógica de um sistema oriundo de um conjunto articulado de regras enunciativas, o qual instaura acontecimentos e coisas: "são todos esses sistemas de enunciados (acontecimentos de um lado, coisas de outro) que proponho chamar de arquivo". Nesse sentido, o arquivo constitui-se por meio do saber e distingue-se pelo acúmulo das coisas ditas, sendo então a "lei do que pode ser dito, o sistema que rege o surgimento dos enunciados como acontecimentos singulares" (FOUCAULT, 2009b, p.170). Dito de outra forma, o arquivo seria não apenas o lugar, nem muito menos o suporte, mas o sistema, isto é, a regra histórica por onde os enunciados acontecem.

A partir dessa premissa, Foucault (2009b) caracteriza-o como montável e selecionável, dado que são os sujeitos subjetivados que definem as características de sua elaboração, sob aspectos e recortes temporais e territoriais. O arquivo é, portanto, uma construção social e histórica de enunciados em situação dispersa e descontínua, sendo assim um objeto raro e singular. Dessa maneira, o arquivo é pensado por Foucault (2000) como:

O conjunto dos discursos efetivamente pronunciados. Esse conjunto é considerado não apenas como um conjunto de acontecimentos que tiveram lugar uma vez por todas e ficaram em suspenso, no limbo ou no purgatório da história, mas também como um conjunto que continua funcionando, se transforma através da história, da possibilidade de aparecer de outros discursos (FOUCAULT, 2000, p.145).

As duas principais técnicas realizadas no interior dos arquivos, que se aproximam da relação com a memória, são a avaliação e a seleção de documentos, conforme ressalta Jardim (1995). Essas atividades são responsáveis por estabelecer a permanência ou a eliminação dos documentos e informações nos arquivos e, consequentemente, da memória. Do ponto de vista dos arquivos:

A eleição da memória consiste, de fato, em decidir, diante de um conjunto de dados, eventos ou informações, quais devem ser privilegiados e quais podem ser abandonados ao possível cancelamento (LOUSADA, 2012, p.64).

A avaliação documental operada na instituição arquivística define quais documentos serão preservados em "fase permanente", após terem cumprido seus objetivos na "fase corrente" e "intermediária". Essa ação tem como base o julgamento dos valores documentais que, 
em síntese, resumem-se aos quadros administrativo-probatórios, históricos, memorialísticos, culturais e informacional-científicos (SCHELLENBERG, 2004). Os arquivos, assim:

[...] incorporam uma vocação social, para criar um espaço especial em que uma determinada ordem de valores prevaleça. As instituições que contêm documentos de arquivo ocupam um espaço alocado dentro e por uma ordem social circundante 3 (BROTHMAN, 1991, p.82, tradução nossa).

A ordem preside a lógica avaliativa e, por conseguinte, classificadora dos documentos. Os arquivistas, na maior parte das vezes, operam, impõem e estabelecem a ordem dos arquivos, seja por vontades políticas institucionais, seja por aspectos individuais ou sociais. Essa ordenação, na perspectiva de Brothman (1991), possui duas tipologias: a primeira diz respeito ao espaço físico, posição dos objetos e pessoas; e a outra se encontra voltada para o aspecto intelectual e os princípios metodológicos profissionais para a organização dos documentos. O processo avaliativo, delineado por uma lógica ordenadora, determina o que será lembrado e esquecido em matéria de informação e memória (COOK, 2003). Os arquivistas, desse modo, tornam-se instrumentos dos agenciamentos voltados para a criação, destruição, modificação, atualização e multiplicação dos sentidos e informações com base em teorias, técnicas e vontades políticas.

Buscando observar a face oculta dos arquivos e suas ordens avaliativas e classificadoras, Cook (2012) apresentou um novo conceito e procedimento para a avaliação documental, a chamada "macroavaliação". Nessa modalidade técnica, o objetivo é o deslocamento da avaliação centrada no conteúdo temático para uma avaliação baseada no contexto e no papel de cada ator social na produção, uso e gestão documental:

A avaliação irá apreciar vozes marginalizadas, ou mesmo silenciadas, da mesma forma cuidadosa com que aprecia textos poderosos e oficiais, e irá buscar evidências de governança em vez de governo (COOK, 2012, p.25).

A "macroavaliação" desloca a abordagem estrutural, funcional e técnica para uma visada, a qual privilegia as vontades de produção e arquivamento, os processos de composição e decomposição e o fluxo das informações que compõem e atualizam constantemente os arquivos:

Dito de outra forma, o discurso teórico arquivístico está mudando de produto para processo, de estrutura para função, de arquivos para arquivamento, de registro para contexto de registro, de resíduo "natural" ou subproduto passivo da atividade administrativa para memória social construída conscientemente e mediada ativamente, "archivalisation" (COOK, 2012, p.5).

Aquilo que constitui os arquivos, portanto, é um princípio de ação intencional destinado à criação, documentação, arquivamento, preservação, guarda e utilização de documentos voltados para a construção das memórias no interior do social. Por esse princípio de ação, encontram-se atrelados os aspectos da "governamentalidade" nas sociedades de controle.

Assim, o arquivo não é um espaço independente, mas um equipamento social que atua no "governo dos homens", por intermédio do que é ali registrado, estabelecendo uma ordem de "governamentalidade", que opera processos de subjetivação por meio de agenciamentos múltiplos e heterogêneos. Construídos e selecionados pelos sujeitos que definem suas características de elaboração (temporais e territoriais), os arquivos constituem, portanto, um conjunto de "enunciados" que, elaborados na condição de "dispositivos de informação" na sociedade contemporânea, atuam a partir e para as constituições de saberes definidores da vida e da morte dos documentos, informações e memórias.

\section{Considerações finais}

As duas principais técnicas de gestão aplicadas nos arquivos (seleção e avaliação) dão forma, qualidade e direcionamento às informações, a partir de ações estruturadas em razões e vontades específicas, configurando, portanto, a subjetivação arquivística. Essas instituições tornam-se, por conseguinte, espaços estratégicos para o desenvolvimento de políticas oficiais da memória. As teorias e as técnicas desenvolvidas em seu interior atuam

\footnotetext{
3 Archival institutions, then, embody a social vocation to create a special space in which a certain order of values prevails. Those institutions containing archival records occupy a space allocated within and by a surrounding social order (BROTHMAN, 1991, p.82).
} 
na enunciação de discursos de memória, agindo sob a forma de um "dispositivo de informação" capaz de capturar os elementos necessários para a governança dos homens, sob os aspectos da identidade, da ideia de nação e de cultura.

Nesse sentido, a memória coletiva constitui um "dispositivo" composto de discursos de verdade, apresentado na condição de arquivo, isto é, como conjunto de regras que facultam o emergir, em uma determinada época, de um tipo de discurso capaz de agir sobre os homens, tornando-os sujeitos de certo conjunto de memórias. Para tanto, articulam-se modos de visibilidade, ocultação, regulação e afirmação de informações sobre o passado que dotam os quadros da memória da capacidade de criar significados semânticos (fazer falar), representacionais (fazer ver) e subjetivos (fabricar sujeitos).
Desse modo, portanto, no interior dos grupos sociais são promovidos agenciamentos temporais e espaciais que conduzem os sujeitos e as instituições a territorializar, desterritorializar, reproduzir, rememorar e representar uma memória social marcada pelas percepções do presente. A informação, os arquivos e as memórias são ativados e inter-relacionados no interior desses "dispositivos", que delineiam tipos específicos de saber, poder e sujeitos submetidos a contextos sociais, políticos e econômicos específicos.

\section{Colaboradores}

Todos os autores contribuíram na concepção e desenho do estudo, análise de dados e redação final do artigo.

\section{Referências}

AGAMBEN, G. O que é um dispositivo? In: O que é o contemporâneo e outros ensaios. Chapecó: Argos, 2009.

BERGSON, H. Matéria e memória. São Paulo: Martins Fontes, 2006.

BROTHMAN, B. Orders of value: Probing the theoretical terms of archival practice. Archivaria, n. 32, p. 78-100, 1991.

COOK, T. Macrovaloración y análisis funcional: la preeminencia de la interacción políticosocial sobre el gobierno. Tabula: Revista de Archivos de Castilla y León, n. 6, p. 87-103, 2003.

COOK, T. A ciência arquivística e o pós-modernismo: novas formulações para conceitos antigos. In: InCID: Revista de Ciência da Informação e Documentação, v. 3, n. 2, p. 2-27, 2012.

DERRIDA, J. Mal de arquivo: uma impressão freudiana. Rio de Janeiro: Relume Dumará, 2001.

FOUCAULT, M. Ditos e escritos II: arqueologia das ciências e história dos sistemas de pensamento. Rio de Janeiro: Forense Universitária, 2000.

FOUCAULT, M. A arqueologia do saber. 7. ed. Rio de Janeiro: Forense Universitária, 2009a.

FOUCAULT, M. História da sexualidade: a vontade de saber. Rio de Janeiro: Graal, 2009b.

FOUCAULT, M. Microfísica do poder. Rio de Janeiro: Graal, 2010a.

FOUCAULT, M. Do governo dos vivos. Rio de Janeiro: Achiamé, $2010 \mathrm{~b}$.

FOUCAULT, M. Do governo dos vivos: curso no Collège de France, 1979-1980. Rio de Janeiro: Achiamé, 2011.

FROHMANN, B. Taking information policy beyond information science: Applying the actor network theory. In: ANNUAL
CONFERENCE OF THE CANADIAN ASSOCIATION FOR INFORMATION SCIENCE, 23., 7-10 Jun, 1995, Alberta. Proceedings... Alberta: Canadian Association for Information Science, 1995.

GONZALÉZ DE GÓMEZ, M. N. Da organização do conhecimento às políticas de informação. Informare, v. 2, n. 2, p. 58-66, 1996.

GONZALÉZ DE GÓMEZ, M. N. Escopo e abrangência da Ciência da Informação e a Pós-Graduação na área: anotações para uma reflexão. Transinformação, v. 15, n. 1, p. 31-43, 2003.

GONZALÉZ DE GÓMEZ, M. N. Regime de informação: construção de um conceito. Informação \& Sociedade: Estudos, v. 22, n. 3, p. 43-60, 2012.

HALBWACHS, M. Les cadres sociaux de la mémoire. Paris: Les Presses Universitaires de France, 1952, p.299.

HALBWACHS, M. Fragmentos dela memoria colectiva. Athenea Digital, n. 2, p. 1-11, 2002.

HALBWACHS, M. A memória coletiva. São Paulo: Edições Vértice, 1990.

JARDIM, J. M. A invenção da memória nos arquivos públicos. Ciência da Informação, v. 25, n. 2, 1995.

LATOUR, B. Jamais fomos modernos: ensaio de antropologia simétrica. Rio de Janeiro: Ed. 34, 1994.

LOUSADA, M. A evolução epistemológica do conceito de avaliação documental na arquivística e sua importância para a construção da memória. R/Cl: Revista Ibero-americana de Ciência da Informação, v. 5, n. 2 p. 63-78, 2012.

LOWENTHAL, D. Como conhecemos o passado? Projeto História, v. 17, p. 63-201, 1998.

MURGUIA, E. I. A memória e a sua relação com arquivos, bibliotecas e museus. In: MURGUIA, E. I. (Org.). Memória: um 
lugar de diálogo para arquivos, bibliotecas e museus. São Carlos: Compacta Gráfica e Editora, 2010. p. 11-32.

POLLAK, M. Memória e identidade social: estudos históricos. Revista Estudos Históricos, v. 5, n. 10, p. 200-212, 1992.

RICOEUR, P. A memória, a história, o esquecimento. Campinas: Unicamp, 2007.

SCHELLENBERG, T. R. Arquivos modernos: princípios e técnicas. 4. ed. Rio de Janeiro: FGV, 2004.

WILKE, V. C. L.; JARDIM, J. M. Dispositivo de informação contemporâneo: considerações preliminares para uma arqueo- genealogia do horizonte informacional em nossa contemporaneidade. In: ENCONTRO NACIONAL DE PESQUISA EM CIÊNCIA DA INFORMAÇÃO, 7., 2006, Marília. Anais... Marília: Ancib, 2006. Disponível em: <http://www.marilia.unesp.br/ sistemas/enancib/viewpaper.php?id=262>. Acesso em:20 jun. 2015.

WILKE, V. C. L. O dispositivo informacional: sobre informação, estado e poder na contemporaneidade a partir do contexto das políticas públicas de inclusão digital do governo federal brasileiro. 2009. Tese (Doutorado Ciência da Informação) - Instituto Brasileiro de Informação em Ciência e Tecnologia, Niterói, Rio de Janeiro, 2009. 